\title{
Sequential wire shifting technique might be in some cases indispensable to acquire adequate pulmonary wedge pressure during right heart catheterization
}

\author{
Grzegorz M. Kubiak ${ }^{1}$, Michał Zakliczyński ${ }^{1}$, Michał Hawranek², Michat O. Zembala ${ }^{1}$, Piotr Przybyłowski ${ }^{1}$, \\ Mariusz Gąsior² \\ 1Department of Cardiac Surgery and Transplantology, SMDZ in Zabrze, Medical University of Silesia in Katowice, Silesian Centre for Heart \\ Disease, Zabrze, Poland \\ ${ }^{2} 3^{\text {rd }}$ Department of Cardiology, SMDZ in Zabrze, Medical University of Silesia in Katowice, Silesian Center for Heart Diseases, Zabrze, Poland
}

Adv Interv Cardiol 2019; 15, 4 (58): 499-502

DOI: https://doi.org/10.5114/aic.2019.90230

Right heart catheterization (RHC), according to current guidelines presented in the Joint Statement of the Polish Cardiac Society's Working Group on Pulmonary Circulation and Association of Cardiovascular Interventions [1], is essential to diagnose pulmonary hypertension (PH), which is a serious limitation in case of heart transplant (HTx) listing. A pulmonary vascular resistance (PVR) value exceeding 3.0 Wood units is associated with raised post-operational mortality [2].

A 60-year old man with ischemic cardiomyopathy had $\mathrm{RHC}$ prior to HTx listing. Initial examination 6 months earlier failed to assess pulmonary capillary wedge pressure (PCWP). Moreover, it provoked acute decompensation with the need of urgent treatment. Several issues may have contributed as the patient presented a severe clinical condition with New York Heart Association class IV, INTERMACS class III. Secondly, heart failure (HF) emerged gradually, which resulted in major dilatation of the ventricles. Thirdly, the patient presented with combined pre- and post-capillary hypertension; hence he would fall within the scope previously described as "out-of-proportion" PH. Likewise, in this clinical state, raised PVR may lead to a progressive dilatation of the pulmonary arteries. The heavily remodelled anatomy of the pulmonary vascular bed may present a challenge that needs a real breakthrough unless the procedure remains incomplete; hence the sequential wire shifting (SWS) technique was introduced. Noticeably, the unequivocal result of PCWP merits the simultaneous assessment of left ventricular end-diastolic pressure during left heart catheterization as the gold standard, especially given that it may lead to misclassification of $\mathrm{PH}$ with all consequences [3].
A 7-F Balton, Poland sheath is inserted by the use of Seldinger's technique. A Swan-Ganz (SG) catheter (Edward Lifesciences, USA) is introduced into the right ventricle in order to perform single beat calibration of the catheter and pressure transducer based on the routine, previously described manner [4]. Subsequently, the catheter and the pressure transducer are disconnected. Latterly the diagnostic EMERALD, Cordis, USA, guidewire $0.035 \times 150 \mathrm{~cm}, 3 \mathrm{~mm}$ J tip wire is inserted into the left pulmonary artery. A multi-purpose (MPA), Cordis diagnostic catheter is introduced with the subsequent removal of the diagnostic wire. A $300 \mathrm{~cm}$ J-tip Whisper ES, Abbott, USA, angioplasty wire is placed via the MPA catheter with subsequent removal of the latter. The clinched angioplasty wire is used as a rail for the introduction of the SG catheter. Notably, the use of a peripheral guidewire might be dangerous due to the risk of distal perforation. The acquired value of PCWP is reliable; moreover, re-evaluation of RV pressure represents excellent concordance with the initial values, and last but not least it enables further calculations of PVR. To access the step-by-step description of SWS please refer to Figure 1 and Table I with further commentaries.

In conclusion, SWS is a safe technique to acquire PCWP in a demanding group of patients with HF coinciding with major dilatation of pulmonary arteries in the course of $\mathrm{PH}$. Theoretically, it might be either initially (in the case of presumably raised $\mathrm{RV}$ systolic pressure in echocardiography) or provisionally (in the case of impaired intraoperational manoeuvrability) implemented in almost all cases. However, its potential contribution to clinical practice requires further evaluation.

\section{Corresponding author:}

Grzegorz M. Kubiak MD, PhD, Department of Cardiac Surgery and Transplantology, SMDZ in Zabrze, Medical University of Silesia in Katowice, Silesian Centre for Heart Disease, 9 Curie-Skłodowska St, 41-800 Zabrze, Poland, phone: +48 32373 38 57, e-mail: gkubiak@sccs.pl Received: 17.06.2019, accepted: 13.07.2019. 

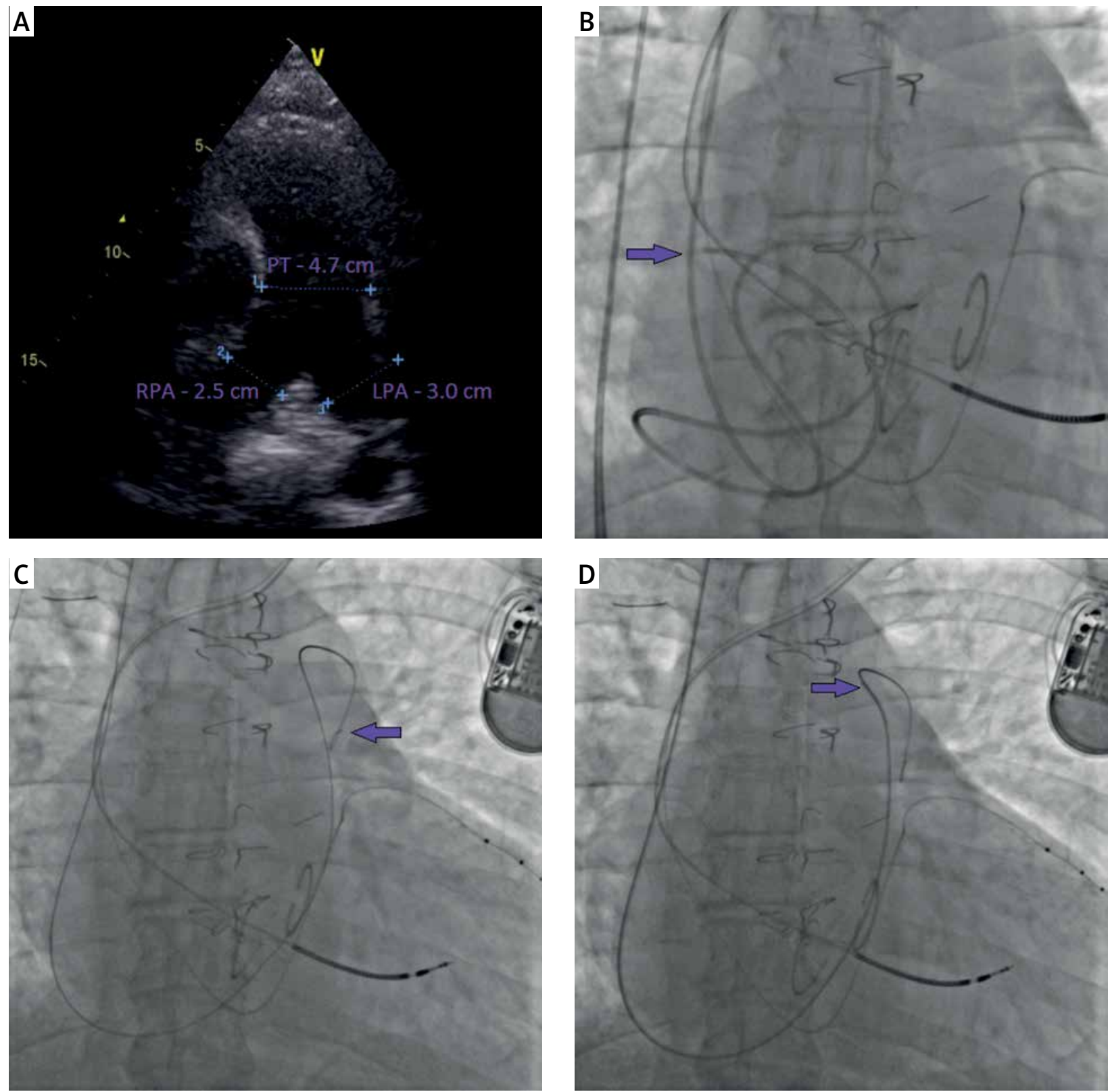

Figure 1. Stages of sequential wire shifting (SWS) technique. A - heavily dilated pulmonary vascular bed, B - distortion of Edward Lifesciences Swan-Ganz (S-G) catheter, irritation of right atrium (velvet arrow) caused atrial flutter with subsequent clinical decompensation, C - diagnostic EMERALD, Cordis, USA, guidewire 0.035 $\times 150 \mathrm{~cm}, 3 \mathrm{~mm} J$ tip wire is inserted into the left pulmonary artery (velvet arrow), D - multi-purpose (MPA), Cordis diagnostic catheter (velvet arrow) is introduced with the subsequent removal of the diagnostic wire 

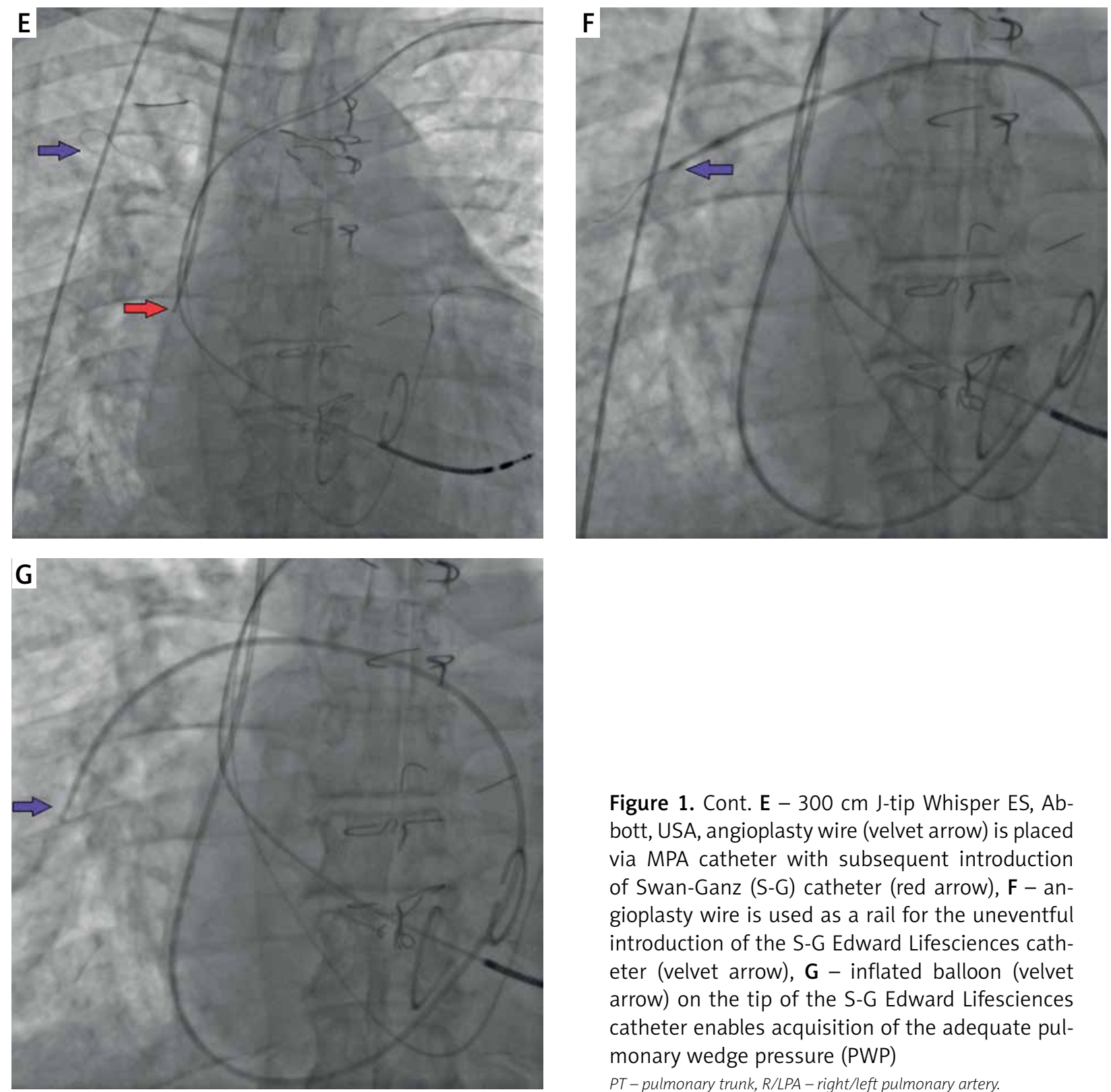

Figure 1. Cont. E - $300 \mathrm{~cm}$ J-tip Whisper ES, Abbott, USA, angioplasty wire (velvet arrow) is placed via MPA catheter with subsequent introduction of Swan-Ganz (S-G) catheter (red arrow), F - angioplasty wire is used as a rail for the uneventful introduction of the S-G Edward Lifesciences catheter (velvet arrow), G - inflated balloon (velvet arrow) on the tip of the S-G Edward Lifesciences catheter enables acquisition of the adequate pulmonary wedge pressure (PWP)

$P T$ - pulmonary trunk, R/LPA - right/left pulmonary artery.

Table I. Hemodynamic parameters obtained during RHC

\begin{tabular}{|c|c|c|c|}
\hline Parameter & Abbreviation & Initial RHC (6.02.2018) & SWS RHC (7.08.2018) \\
\hline Systemic blood pressure & SBP & 105/70 mm Hg & $112 / 82 \mathrm{~mm} \mathrm{Hg}$ \\
\hline Mean right atrial pressure & mRAP & $10 \mathrm{~mm} \mathrm{Hg}$ & $10 \mathrm{~mm} \mathrm{Hg}$ \\
\hline Right ventricular systolic pressure & RVSP & $59 \mathrm{~mm} \mathrm{Hg}$ & $67 \mathrm{~mm} \mathrm{Hg}$ \\
\hline Mean pulmonary artery pressure & mPAP & $41 \mathrm{~mm} \mathrm{Hg}$ & $43 \mathrm{~mm} \mathrm{Hg}$ \\
\hline Pulmonary capillary wedge pressure & PCWP & NA & $34 \mathrm{~mm} \mathrm{Hg}$ \\
\hline Transpulmonary gradient & TPG & NA & $9 \mathrm{~mm} \mathrm{Hg}$ \\
\hline Cardiac output & $\mathrm{CO}$ & $4.4 \mathrm{l} / \mathrm{min}$ & $4.9 \mathrm{l} / \mathrm{min}$ \\
\hline Cardiac index & $\mathrm{Cl}$ & $2.14 \mathrm{l} / \mathrm{min} / \mathrm{m}^{2}$ & $2.41 \mathrm{l} / \mathrm{min} / \mathrm{m}^{2}$ \\
\hline Pulmonary vascular resistance & PVR & NA & 1.83 Wood units \\
\hline
\end{tabular}

RHC - right heart catheterization, NA - not applicable. 


\section{Conflict of interest}

The authors declare no conflict of interest.

\section{References}

1. Kurzyna M, Araszkiewicz A, Błaszczak P, et al. Summary of recommendations for the haemodynamic and angiographic assessment of the pulmonary circulation. Joint statement of the Polish Cardiac Society's Working Group on Pulmonary Circulation and Association of Cardiovascular Interventions. Kardiol Pol 2015; 73: 63-8.

2. Costard-Jäckle A, Fowler MB. Influence of preoperative pulmonary artery pressure on mortality after heart transplantation: testing of potential reversibility of pulmonary hypertension with nitroprusside is useful in defining a high risk group. J Am Coll Cardiol 1992; 19: 48-54.

3. Halpern SD, Taichman DB. Misclassification of pulmonary hypertension due to reliance on pulmonary capillary wedge pressure rather than left ventricular end-diastolic pressure. Chest 2009; 136: 37-43.

4. Brimioulle S, Wauthy P, Ewalenko P, et al. Single-beat estimation of right ventricular end-systolic pressure-volume relationship. Am J Physiol Heart Circ Physiol 2003; 284: H1625-30. 